\section{AUTHORS’ REPLY}

Dear Fabiano Timbó Barbosa,

We sincerely appreciate your comments, which will certainly contribute to better understanding of this trial.

First, we should highlight that our inclusion criteria were based on the proposal by Shoemaker et al. ${ }^{(1)}$ to characterize high-risk surgical patients with similar prognoses. This method was also used in another recent trial ${ }^{(2)}$. Therefore, this study's population consists of a well-defined group with a high risk of death. The population was chosen for the sake of sample homogeneity. This can be confirmed by our findings of high mortality $(25.8 \%)$ and complication $(54.5 \%)$ rates, despite the fact that most of the procedures were elective in a population with ASA class II risk.

Regarding sample size calculation, please note that this was an observational, non-interventional study. This observation was conducted for the time allowed by the institution's Ethics Committee (six months). Therefore, it was not possible to calculate the sample size a priori. This, however, does not invalidate our findings, as significant differences were observed with a very low probability of casual findings. As commented in our report, we considered this as a possible limitation. However, we wish to emphasize that cohort studies, as a group, have inherent limitations and better powered studies are warranted to confirm these findings.

Finally, the distribution of the data was analyzed with calculation of Skewness (between -1 and +1 ) and Kurtosis (up to $3^{(3)}$ ) and with the Kolmogorov-Smirnov test (for values above 0.05). However, even when these tests showed normal distribution, but when the coefficients of variation from the mean were high, we chose to conduct non-parametric tests. We accepted the $p$ value from the parametric test only when both test types showed significant results, defined as $\mathrm{p}<0.05$.

Once again we thank you for your comments and for the opportunity to clarify our study.

Sincerely,

João Manoel Silva Junior, Amanda Maria Ribas

Rosa Oliveira, Bruno Ricciardi Silveira, Ulisses Pinto Ferreira, Rodrigo Natal Albretht, Tiago Bertacini Gonzaga, Ederlon Rezende

Serviço de Terapia Intensiva do Hospital do Servidor Público Estadual "Francisco Morato de Oliveira" HSPE-FMO - São Paulo (SP), Brasil.

\title{
REFERÊNCIAS
}

1. Shoemaker WC, Appel PL, Kram HB, Waxman K, Lee TS. Prospective trial of supranormal values of survivors as therapeutic goals in high-risk surgical patients. Chest. 1988;94(6):1176-86.

2. Arantes AS, Christiano Júnior AC, Abreu SP, Moraes JMMF, Gandolfi JV, Leite LG, Lobo SM. Doses baixas de dobutamina e fluidos no pós-operatório de pacientes de alto risco: efeitos sobre a oxigenaçáo tecidual, resposta inflamatória e morbidade. Rev Bras Ter Intensiva. 2007;19(1):5-13

3. Joanes DN, Brânquia CA. Comparando medidas do skewness e do kurtosis da amostra. J Soc Estatística Real (Série D): O Statistician. 1998;47(1):183-9. 